CUPAUAM. 16-1989, 127-147

\title{
LA GENESIS DE LA ESTRUCTURA URBANA EN LA ESPAÑA ANTIGUA
}

\author{
Manuel Bendala Galan \\ UNIVERSIDAD AUTONOMA DE MADRID
}

\section{Resumen}

El artículo aborda el orígen de la estructura urbana en la España antigua, con exposición previa de los principios doctrinales y metodológicos de los que se parte. Se concluye el comienzo de la estructura urbana con el Bronce Final tartésico, y se argumenta su relación, de ruptura, con las etapas anteriores y de clara continuidad con las posteriores.

\section{Summary}

This paper treats of the origin of urban structure in Ancient Spain, with previous explanation of doctrinal and methodological principles. The conclusions point to the beginning of urban structure during the Tartesian Late Bronze Age, a new event in the cultural evolution of the South of the Iberian Peninsula which implies a rupture with earlier periods and a clear continuity with the subsequent urban development.

"El hombre culto, cuya alma plasmó antaño el campo, cae prisionero de su propia creación, la ciudad, y se convierte entonces en su criatura, en su órgano ejecutor y, finalmente, en su víctima" (O. Spengler).

"Lo que el historiador de las civilizaciones puede afirmar, mejor que cualquier otro, es que las civilizaciones son realidades de muy larga duración. Por lo general sólo son perecederas sus flores más exquisitas, sus éxitos más excepcionales; pero las raíces profundas subsisten a muchas rupturas, a muchos inviernos" (F. Braudel). 
Entre las múltiples formas de abordar nuestra historia pasada, la de plantearla en función del urbanismo, de su génesis y evolución, es una propuesta llena de interés y cargada de posibilidades; sigue la pista a una cuestión medular, que proporciona una visión de las cosas extraordinariamente fructífera, por lo que no ha de extrañar que cuente, fuera y dentro de nuestro país, con numerosos cultivadores.

Se trata de comprender la historia de la cultura -en nuestro caso de la cultura antigua- a partir de la contemplación de las realidades estructurales, y la estructura cultural tiene desde la Antigüedad a la ciudad como uno de sus elementos definitorios y definitivos. Con la ciudad, la emanación propia y más visible de la compleja trama cultural en que consiste la organización urbana o la estructura urbana, empieza verdaderamente la historia universal: "La historia universal es la historia del hombre urbano", decía O. Splengler (1966 II, 111); y puede decirse que con la ciudad empieza la Historia, entendida, según la convención tradicional, como etapa que supera y sucede a las largas fases de la historia humana caracterizadas por la existencia de formas culturales más primitivas, o menos evolucionadas, que englobamos bajo el manto del infortunado término de Prehistoria.

Suele decirse que la Historia comienza con la aparición de la escritura, pero sería más adecuado considerar, para una mejor adecuación entre la historia real y la escrita con objeto de sistematizarla y comprenderla desde el presente, que comienza con la aparición de las formas avanzadas de cultura propias de la ciudad, de las que el uso de la escritura es uno de sus corolarios. La importancia de la ciudad, y la convicción de que su existencia supone una forma definitiva de maduración de la especie humana, dotada desde entonces del superior instinto colectivo que supone la conciencia histórica, son ideas que calaron profundamente en autores antiguos como Aristóteles, que consideraba al hombre un zoon politikón, en tanto en cuanto alcanza su plenitud como especie en el ámbito de la polis, de la ciudad, a la que tiende por naturaleza (La Política 1,1). El ya citado Spengler, en su misma línea, dirá después: "Todas las grandes culturas son culturas ciudadanas. El hombre superior de la segunda era es un animal constructor de ciudades" (1966, II, 111). Se entiende bien que para Tito Livio, la historia de Roma, que es lo mismo que decir de los romanos, comenzara con la fundación de la ciudad: ab Urbe condita. Y es idea que ha sido convenientemente subrayada por los tratadistas modernos.

En efecto, la sustancial correlación entre maduración sociológica, historia y ciudad es uno de los ejes de la argumentación de un clásico como Fustel de Coulanges. Según él, la vocación de perpetuación consustancial a la ciudad, desarrolló la conciencia histórica, subrayando la importancia de la nueva cohesión de la comunidad desde el momento de la fundación de la ciudad, que se garantizaba con importantes lazos ideológicos y religiosos: “...la historia comenzaba con el acto de la fundación y mencionaba el nombre sagrado del fundador. Continuaba con la leyenda de los dioses de la ciudad, de los héroes protectores." [...] "Este género de historia local, empezaba con la fundación, porque lo anterior a ella en nada interesaba a la ciudad. Por esto lo antiguos ignoraron absolutamente los orígenes de su raza. Tampoco consignaban más que los acontecimientos en que la ciudad había intervenido... Cada ciudad tenía su historia especial, como tenía su religión y su calendario" (Coulanges, 1983, 210-211). Y es una idea subrayada recientemente por J. Rykwert, en su precioso libro sobre La idea de ciudad. Antropología de la forma urbana en el mundo antiguo (Madrid 1985, 12 ss.). Pero me interesa más volver a las realidades estructurales, tras esta breve consideración de la conciencia histórica que se genera por la asunción consciente o inconsciente del peso de esas realidades.

Empecemos por subrayar un hecho de índole metodológica. El enfoque de la historia antigua de Hispania a partir de sus manifestaciones urbanas es un antídoto contra los peligros que, a mi 
juicio, entrañan las concepciones historiográficas tradicionales, que tienden a verla como una sucesión de episodios estudiados y considerados con una cierta o total autonomía: la civilización tartésica, la colonización fenicia, la colonización griega, el dominio púnico, la conquista romana y la consiguiente romanización... Incluso es normal que cada etapa o aspecto sea campo de ocupación de especialistas distintos, cada uno de los cuales tiende a subrayar la identidad de su período de interés, generalmente con el "lastre" de habérselas con herencias de etapas anteriores, no siempre entendidas o valoradas adecuadamente, aparte de que pueda terminar con unas consideraciones sobre la perduración -si no es que se utiliza el inconveniente término de "perviviencia"- de los contenidos culturales de la etapa considerada en las subsiguientes.

Es, en definitiva, una forma de observar las realidades históricas que -dicho en términos coloquiales- obliga a cierto "bizqueo", con los desenfoques y deformaciones consiguientes. Lo cierto es que, con todo, se hace la historia poniendo en primer plano los fenómenos de coyuntura, lo que da lugar a discursos erráticos, en tanto en cuanto se pretende explicar las coyunturas como hechos cerrados, comprensibles en sí mismos, con principios y finales propios, aunque las realidades estructurales obligan, tozudamente, a mirar fuera del campo supuestamente autónomo. Es preciso caer en la cuenta de que la única forma de entender adecuadamente las realidades objeto de análisis es abarcándolas en sus verdaderas dimensiones, que son las de la estructura a la que pertenecen, $y$ determinar qué papel juegan en ella.

Puede advertir el avisado lector que todo esto no es otra cosa que asumir los planteamientos expuestos hace ya algún tiempo por Fernand Braudel: historiar en función de las realidades de la larga duración, la longe durée. Y si, como propone el historiador francés, se bucea en busca de las realidades estructurales más profundas, las de larga y muy larga duración, topamos con las ciudades como los elementos más expresivos de entre aquéllos que reflejan o materializan las estructuras culturales.

Lo que Braudel escribe a propósito de la estructura en general, podemos traerlo a colación y aplicarlo punto por punto a la estructura urbana, en cuanto ilumina a la perfección las ideas que subyacen a los planteamientos que siguen. "Para nosotros, los historiadores" -dice Braudel-, "una estructura es indudablemente un ensamblaje, una arquitectura; pero, más aún, una realidad que el tiempo tarda enormemente en desgastar y en transformar. Ciertas estructuras" -como las urbanas, añado- "están dotadas de tan larga vida que se convierten en elementos estables de una infinidad de generaciones: obstruyen la historia, la entorpecen y, por tanto, determinan su transcurrir" (Braudel, 1968, 70). Como conclusión de su pensamiento, escribe: "Entre los diferentes tiempos de la historia, la larga duración se presenta, pues, como un personaje embarazoso, complejo, con frecuencia inédito... Para el historiador, aceptarla equivale a prestarse a un cambio de estilo, de actitud..., a familiarizarse con un tiempo frenado... La totalidad de la historia puede, en todo caso, ser replanteada como a partir de una infraestructura en relación a estas capas de la historia lenta. Todos los niveles, todos los miles de niveles, todos los miles de fragmentaciones del tiempo de la historia, se comprenden a partir de esta profundidad, de esta semi-inmovilidad; todo gravita en torno a ella" (Braudel, 1968, 74). Parece que nuestro autor estuviera pensando especificamente en la ciudad y en la estructura que la integra.

Si nos planteamos la historia de nuestra cultura buscando de manera radical su más definitoria infraestructura, nos toparemos con que se convierte aquélla, la faena de historiar, en gran medida en la puesta en evidencia de la progresiva configuración de nuestra estructura urbana; y es una estructura en algún modo única, que se inicia en un momento determinado y llega a nuestros días, con las evidentes ampliaciones, alteraciones y modificaciones. Su historia es, en 
cierta manera, una historia lineal, que subyace a todos los episodios, como dice Braudel, sin comenzar y acabar con cada uno de ellos. Parafraseando un célebre principio afecto a las realidades físicas, puede decirse que la estructura urbana -precisamente, entre otras cosas, por lo que tiene de realidad física- se comporta, una vez creada o iniciada, como la materia, que ni se crea ni se destruye, solamente se transforma.

El paso definitivo -y decisivo- entre lo que llamamos Prehistoria y la Historia, estriba en la configuración, o el comienzo de ella, de la estructura urbana, a partir de lo cual, los fenómenos de perduración de la estructura pesarán contínuamente en los episodios históricos que se van sucediendo en el tiempo, determinando aspectos importantes, al menos, en el plano de las realidades culturales. Un análisis menudo de esta cuestión exigiría un largo ensayo imposible de abordar aquí. Sólo, por ejemplo, la relación de dependencia o de independencia, entre la realidad material de las estructuras urbanas, y los grupos humanos que la ocupan y la usan y su cultura en términos generales, puede ser objeto de una interesante y larga reflexión. Me conformaré ahora con limitar mi atención a discutir brevemente cuándo puede establecerse el comienzo de la estructura urbana de Hispania, y cómo desde la conciencia de la continuidad de la estructura urbana, son entendibles de mejor manera, y abordables para el historiador con más posibilidades, los episodios y las épocas que se suceden en nuestra Antigüedad.

En función del planteamiento expresado, es un problema principal determinar cuándo, cómo y por qué, empieza a configurarse en España su definitiva estructura urbana. Es un problema de largo alcance, muy debatido entre historiadores y arqueólogos, complicado y enriquecido a un tiempo en los últimos años, por el considerable aumento de nuestros conocimientos arqueológicos y por la aplicación de diversos modelos teóricos que tratan de definir los conceptos de Estado y su posible plasmación en determinadas fases o culturas de nuestra Prehistoria, al menos desde el Calcolítico y la Edad del Bronce. Sin entrar de lleno en la polémica, parece ampliamente aceptado que durante esos períodos de la Prehistoria, y pensando ahora fundamentalmente en el área europea, el desarrollo cultural trajo consigo fórmulas de organización social cada vez más complejas y jerarquizadas, así como sistemas de explotación agropecuaria y técnicas de extracción minera y de aprovechamiento de los metales progresivamente mejores, superadores de la mera producción de subsistencia, que condujeron en conjunto a la aparición en algunas zonas determinadas de las culturas más complejas basadas en la vida ciudadana.

El paso no se dió a la vez en todas partes, y en Europa, por razones bien conocidas, la incorporación a la vida urbana se dió primero en el área mediterránea, empezando por los paises de su cuenca oriental, más directamente beneficiados del contacto con las grandes civilizaciones del Oriente Próximo y Egipto. No hace falta subrayar la importancia que, para el ámbito europeo, tuvieron la cultura minoica y, sobre todo, la posterior consolidación y expansión de la micénica. En cualquier caso, la irradiación de la vida urbana por amplios sectores de la cuenca mediterránea, en un fenómeno, por otra parte, bastante rápido y unitario, introdujo un importantísimo factor de diferenciación entre las culturas urbanizadas y las que no lo estaban, resumible en una frase que tomo de un reciente estudio de conjunto sobre la Prehistoria europea: "Italia, el sur de Francia y ciertas áreas de la Península Ibérica mantenían, desde finales del segundo milenio, estrechas conexiones con la Europa central. Pero a partir del siglo VIII a.C., la situación varió -sustancialmente: las tierras mediterráneas se diferenciaron rápidamente de la Europa situada al norte de los Alpes y quedó definitivamente trazada la división entre el mundo clásico y el mundo bárbaro" (Champion, Gamble, Shenan y Whittle, 1988, 317-318). 
La frase requiriría matizaciones, entre otras cosas en la cronología indicada, que habría que ajustar a cada zona de Europa, pero resume acertadamente un fenómeno importante para la Historia Antigua europea, subrayado por sus autores a la hora de tratar de la aparición de las ciudades y de la organización política de la ciudad-estado. Una de las facetas principales de tal fenómeno, al plantearlo en términos de mundo clásico versus mundo bárbaro, queda explicitada al apuntar, de esa manera, a un hecho cargado de consecuencias: el de las particulares relaciones que se originan entre ambos mundos una vez que uno de ellos se ve impulsado por la dinámica interna que se desencadena en el seno de las sociedades urbanas.

Prácticamente consustanciales a las ciudades son las tendencias expansionistas, derivadas de una concurrencia de factores habituales, como el aumento de la población -por la subida del nivel de vida y el bienestar en general, y por la necesidad creciente de mano de obra que atienda a las exigencias de una economía cada vez más diversificada-, la multiplicación de las necesidades de víveres, de nuevas tierras para el cultivo, etc. No extrañará, por ello, que se originaran pronto corrientes de colonización, una de las principales vías de expansión de las triunfantes fórmulas sociopolíticas y económicas de la ciudad, con efectos de gran trascendencia en la trayectoria del llamado "mundo bárbaro".

En efecto, las zonas no urbanizadas que fueron incluyéndose en el radio de atención y de acción de los intereses de las sociedades urbanas, ya sea por efecto directo de la colonización o, más indirectamente, por los múltiples contactos que iba originando un comercio cada vez más internacionalizado -con el acicate fundamental de la búsqueda de metales-, registran complejos fenómenos de dependencia, o de aculturación y potenciación socioeconómica, que conducen en ocasiones a una decidida incorporación a las formas de vida urbanas.

La Península Ibérica es una de estas regiones, lejana y muy periférica, en principio, respecto de los focos más antiguos de desarrollo de la vida urbana en el Mediterráneo oriental, y con características propias derivadas de factores geográficos y culturales muy acusados, que dieron a los contactos con las culturas de vanguardia ciudadana un sello propio. El desarrollo de importantes focos culturales durante el Calcolítico y la Edad del Bronce, la situación geográfica (en el extremo occidental del Mediterráneo y su apertura al Atlántico), y la posesión de buenos campos para la economía agropecuaria y, sobre todo, de abundantes recursos mineros, están en la base de un proceso complejo de incorporación a la vida urbana, cuya delimitación y caracterización sigue prestándose a una controvertida discusión científica entre los especialistas.

Se me perdonará la incorporación, a los planteamientos expuestos hasta ahora en el presente artículo, de no pocas obviedades, pero me ha parecido necesario desarrollar completamente mis puntos de partida, por elementales que fueran, para de la manera adecuada abordar uno de los meollos de la aludida discusión: el de si la aparición de la vida urbana en la Península en fruto de la evolución interna de las culturas prehistóricas o resultado de un impulso externo.

Sobre ésto se mantienen actitudes o hipótesis diferentes. No se ha apagado todavía, por ejemplo, el eco de proposiciones históricas que defendían que las primeras ciudades surgen en España como consecuencia de la conquista romana, considerando lo anterior un estadio de carácter preurbano o protourbano; o se sostenía que las primeras ciudades aparecen como un fenómeno independiente de su propia evolución cultural, limitadas en época prerromana a las fundaciones coloniales, como la fenicia Gadir o la griega Emporion. En el extremo contrario figuran aquellas hipótesis que defienden el carácter urbano de determinadas culturas, al menos desde la Edad del Bronce, con El Argar como su facies más característica y contemplada a estos efectos. De todo ello hemos tenido ocasión de ocuparnos en un trabajo reciente (Bendala, 
Fernández Ochoa, Fuentes y Abad, 1987), por lo que, más que entrar en detalles, el objetivo aquí es profundizar en aspectos teóricos que entonces no quedaron explícitos, y entrar en las consecuencias epistemológicas que se derivan de ellos, siempre con aplicación al caso concreto que nos ocupa, el de la génesis del urbanismo hispano.

Si contemplamos el urbanismo hispano desde tiempos más recientes y seguros, para retroceder a los más antiguos, en los que el urbanismo pasará a ser problemático y después, más atrás en el tiempo, inexistente, podemos partir de la época romana, en la que no es discutible la plena expansión de la ciudad en Hispania. Mirando a las etapas inmediatamente anteriores a la conquista, es también segura la existencia de una amplia expansión de la estructura urbana por el mediodía y el este de la Península, sin la que no es posible entender su rápida incorporación al Imperio romano, fenómeno ampliamente analizado por bastantes autores -por ejemplo, en el coloquio sobre Los asentamientos ibéricos ante la romanización Casa de Velázquez, Madrid (1986), 1987- y por mí mismo en algunos trabajos (Bendala, 1981 y 1987 b).

El protagonismo de la colonización en el arraigo de la ciudad en la Hispania prerromana nadie lo discute, y tampoco que la inicial acción colonial en la periferia costera fue seguida de una importante progresión de los fenómenos de aculturación -y en algún caso, de presencia directa- hacia el interior, tanto en el ámbito fenicio como en el griego, con las consecuencias lógicas en los diferentes planos culturales, entre ellos el correspondiente a los urbanos y urbanísticos. En este marco hay que situar la maduración de la civilización ibérica, la más personal y prestigiosa de nuestra protohistoria. La investigación actual está prestando la debida atención al estudio de la estructuración urbana y territorial de los diferentes ámbitos ibéricos, aún no bien conocida, y con bastantes aspectos problemáticos y oscuros. De ello se tiene un buen estado de la cuestión en un libro de reciente publicación: Iberos. Actas de las I Jornadas sobre el Mundo Ibérico (Ruiz Rodríguez y Molinos Molinos, ed.,1987).

Pero una nueva cuestión se suscita al considerar que tampoco parece que la colonización de fenicios y de griegos fuera el factor primero y único de la implantación y la irradiación de las formas de vida urbanas en la España antigua. El conocimiento cada vez más profundo de la colonización fenicia y de sus modos y formas de operar (Aubet, 1987), ponen de relieve que la actividad de los fenicios en la época arcaica, la que se remonta al siglo VIII a.C., nucleizada en este extremo del occidente mediterráneo en el establecimiento de un puerto principal de comercio, Gadir, y una serie de establecimientos costeros de apoyo en el Mediterráneo, sólo era posible y efectiva por el contacto con una organización capaz de suministrarle las materias primas que pretendía obtener, y con la cantidad y la regularidad que hicieran rentable el esfuerzo colonizador.

Es ya bien conocido que, en efecto, la acción fenicia tuvo su éxito en el contacto con la organización cultural propia del Bronce Final del mediodía español, primera etapa de la civilización tartésica, según se admite de forma generalizada. Los datos arqueológicos referidos a esta etapa del Bronce Final tartésico acreditan la existencia para entonces de una organización social y económica bastante avvanzada, en la que puede percibirse el comienzo de una verdadera estructuración urbana.

La primera etapa de la civilización tartésica, que por los rasgos de su cultura material -y para diferenciarla del período posterior, sometido a la influencia fenicia- hemos propuesto definirlo como "período geométrico" (Bendala, 1979; Abad, 1979; Bendala, 1986a), representa ya un considerable grado de desarrollo, tan ampliamente subrayado por los especialistas que apenas precisa de mayor argumentación. Es una etapa ciertamente de perfiles no del todo definidos por 
la investigación (Bendala, 1990a), que se extiende por un período anterior a la colonización fenicia relativamente amplio -desde muy cerca, seguramente, del cambio de milenio-, de la que se posee la suficiente información como para considerar insostenibles algunas valoraciones históricas que, demasiado decididas a subrayar la importancia de la colonización fenicia, consideran a la sociedad del Bronce Final simple y poco jerarquizada, practicante de una economía de subsistencia limitada a la agricultura y la ganadería, y ajena a las actividades mineras y metalúrgicas, que sólo emprenderán por obra de la aculturación fenicia (González Wagner, 1983).

La realidad es bien distinta. En principio, abundan los datos para deducir la práctica de una intensa actividad metalúrgica, capaz de producir amplios excedentes, pese a la posesión de una tecnología muy modesta, o rudimentaria, si se quiere, tecnología que, por otra parte, no parece que modificara la presencia fenicia en algunas de sus facetas. Las conclusiones de Blanco y Rothenberg sobre la minería onubense, foco principal de la tartésica, son bien explícitas: "Después de un período aparentemente largo de estancamiento cultural en el suroeste peninsular, durante la Edad del Bronce Media, reflejada en la ausencia total de restos de esta época en los yacimientos metalúrgicos explorados por nuestra prospección, la Edad del Bronce Tardía se ofrece como una etapa de renovada y extensa actividad minera y metalúrgica en Huelva". ..."La evolución de la tecnología del metal alcanza entonces un nuevo estadio: en lugar del cobre puro y arsenical de las épocas anteriores, nos encontramos con bronces de estaño...". "La tecnología de la fundición, a juzgar por la estratigrafía de las escorias de la Corta del Lago y de otros yacimientos, no experimentó ningún cambio cuando la producción de metal del Bronce Tardío recibió nuevo impulso de los mercaderes fenicios..." (Blanco y Rothenberg, 1981, 170-171). En el marco de la exploración arqueometalúrgica de Huelva que condujo al estudio con las conclusiones acabadas de citar, se excavó en el poblado metalúrgico de Chinflón, en término de Zalamea la Real, cerca de Riotinto, y el resultado fue comprobar la actividad de un poblado del Bronce Final tartésico, aproximadamente entre fines del siglo IX y comienzos del VII a.C., en el que no se detectan elementos coloniales fenicios (Pellicer y Hurtado, 1980).

La dedicación a la minería y a la metalurgia de la población tartésica precolonial esta hoy día fuera de discusión, y con un notable nivel técnico (Rovira, 1987), aún reconociendo que la incidencia fenicia sería de importancia decisiva para reorientar su oferta y su dedicación, incluyendo una particular atención a la explotación de la plata (Aubet, 1987, 243 ss.; Ruiz Mata, 1989a). El poblado metalúrgico de San Bartolomé de Almonte (Huelva) muestra, desde fines del siglo IX y comienzos del siglo VIII a.C., la actividad de una comunidad puramente tartésica dedicada al laboreo de la plata, quizá pensando desde muy pronto en una producción destinada al mercado controlado por los gadeiritas, pero, insisto, realizada por tartesios, que debían de seguir manteniendo el control de las cuencas mineras (Ruiz Mata, 1981; Ruiz Mata y Fernández Jurado, 1986). Recientemente, en la Peña Negra de Crevillente (Alicante), se ha documentado un principal foco de fabricación de espadas, puntas de lanza, hachas y otros objetos de bronce, de la tipología que se considera propia del llamado Bronce Atlántico, en un contexto de Bronce Final muy directamente relacionado con el tartésico y con el horizonte de Cogotas I, y en fechas del siglo VIII a.C. Los indicios de actividad metalúrgica desde la primera fase del poblado, que debe remontarse al siglo IX a.C., y su gran desarrollo inmediatamente después -aún en su primera etapa precolonial -, constituyen datos decisivos para el conocimiento de la metalurgia y la distribución de sus productos en las etapas del horizonte cultural en que se inicia la vida del importante yacimiento alicantino (Ruiz Gálvez, 1990); no está de más recordar que, por sus contenidos culturales y por su ubicación geográfica, se ha querido identificar este yacimiento de Peña 
Negra con la ciudad de Herna, citada por Avieno como la que señalaba en el sudeste el límite de los territorios tartésicos (González Prats 1983 y 1990).

El grado de complejidad social, de jerarquización, del Bronce Final tartésico se barrunta en testimonios arqueológicos como las estelas grabadas de guerreros, depositarias, no sólo de lo que a primera vista se contempla -la representación de una fuerte casta guerrera-, sino también de símbolos y de alusiones a complejos ritos, comprensibles sólo en función de las exigencias de dirigentes de una sociedad altamente jerarquizada (Bendala 1977 y 1987 c). Se perciben, incluso, muestras de jerarquía en el marco del propio grupo dirigente al que corresponden las estelas, por el diferente nivel de sus representaciones y por la exaltación del difunto que suponen estelas como la de Ategua y otras de parecida complejidad. Falta, sin duda, una información arqueológica y literaria más completa, pero, según lo que se deduce de las estelas, no se hace imposible pensar en oligarquías de corte aristocrático y en formas de poder unipersonales, cercanos o equivalentes al de las monarquías documentadas en otras culturas mediterráneas de la época. Recuérdese que, para el mundo propiamente tartésico, se cuenta con el testimonio referido al rey Argantonio y otros que, aunque tienen facetas problemáticas, parecen apoyar la existencia de monarquías en Tartessos (Caro Baroja, 1971).

Un postulado en el sentido indicado tiene una estupenda apoyatura más en otro hecho constatado arqueológicamente: la amplia irradiación de la cultura del Bronce Final tartésico. Con un alto grado de homogeneidad, aparece extendida desde los focos nucleares del bajo Guadalquivir hasta bien dentro de las tierras extremeñas - recuérdense la expansión de las estelas de guerreros o la caracterización de yacimientos como Medellín (Almagro Gorbea, 1977)- y del sudeste y el levante de la Península. Se habla ya, con naturalidad, de verdaderas provincias tartésicas en lugares tan relativamente alejados como el foco del sudeste, donde el yacimiento de Los Saladares, en Orihuela (Alicante), puso en guardia acerca de la clara expansión hacia esa zona del Bronce Final tartésico (Arteaga y Serna, 1974 y 1975), corroborada después en otros yacimientos, como el citado de la Peña Negra de Crevillente. Los datos arqueológicos no venían sino a corroborar lo que en las fuentes literarias se contiene acerca de la extensión de la cultura tartésica.

El hecho es que una irradiación cultural tan vasta, y tan relativamente homogénea -y piénsese a estos efectos en el riguroso seguimiento de las fórmulas que configuran los grabados de las estelas de guerreros- sólo es entendible en una sociedad notablemente cohesionada, con contactos frecuentes o regulares entre los diferentes ámbitos por los que se extiende, para los que no faltan testimonios de actividades mercantiles evidentes (últimamente: Aubet, 1990). El estudio de los tipos cerámicos y de las pastas permiten afirmar esta movilidad de productos por vía comercial, y apuntan a un fenómeno de gran interés, aún insuficientemente conocido (Galván, 1986). En el marco de esta complejidad social y económica, necesitada de formas de control y de una burocracia creciente, tiene cabida un fenómeno tan capital como la existencia de escritura. Muy mal conocida todavía para las etapas más antiguas, es ya un hecho sorprendente el que esté documentada desde el Bronce Final, en grafitos realizados sobre cuencos bruñidos, característicos de la fase precolonial. Sin entrar ahora en una cuestión -la del orígen de la escritura tartésica - que desborda el objetivo del presente escrito y, también, el ámbito de mis propias investigaciones, no quiero dejar de aludir a la importancia que para la explicación del antiguo silabario tartésico tiene la reciente comprobación arqueológica de contactos indudables con el mundo micénico, barruntados en tantas cosas, pero definitivamente probados ahora con el hallazgo de cerámicas micénicas en Andalucía (Martín de la Cruz, 1988 y 1990). 
Bastaría con un conocimiento arqueológico decantado en las característica hasta ahora subrayadas del Bronce Final tartésico, para esbozar la hipótesis de que le fuera propio el nivel de desarrollo que corresponde a una sociedad urbana, o protourbana si se quiere, como se denomina a situaciones parecidas en otros ámbitos geográficos y culturales, aunque próximos en su problemática al que nos ocupa, como es el caso de la Península itálica (por ejemplo, recientemente: Peroni, 1989, 462 y passim). Pese a los inconvenientes que tiene la proliferación de términos de este tipo, puede convenir en este caso el de protourbano para designar una etapa inicial de la estructura urbana en la que no se han desarrollado todavía algunos de sus aspectos básicos, fundamentalmente el nivel urbanístico y arquitectónico de sus núcleos de hábitat, aunque estén dados, y en suficiente grado, los rasgos que caracterizan el modelo de ocupación territorial en función del nivel social y, sobre todo, de las exigencias económicas propias de la ciudad.

Es bien sabido que el conocimiento de los núcleos de habitación del Bronce Final tartésico es muy limitado, dedicados los arqueólogos, por la necesidad de obtener datos con los que elaborar el armazón histórico y por otras razones fáciles de entender, más a obtener secuencias estratigráficas que a estudios en extensión de los yacimientos, lo que, además, comporta serias dificultades. Se tiene, sin embargo, una amplia información, con numerosas muestras de los procesos culturales, que corroboran, entre otros, un hecho principal: el de que con el Bronce Final se configura el cuadro básico de la organización urbana y territorial que seguirá vigente en las etapas posteriores. Dicho de otra manera, el paisaje antropizado del mediodía espańol, que gravita sobre centros con determinadas funciones económicas, administrativas, estratégicas, militares y otras, empieza a configurarse con toda claridad en el Bronce Final tartésico.

Desde el punto de vista urbanístico o monumental, esta etapa es de una sorprendente pobreza, aunque no tan sorprendente si se la compara con las de las demás civilizaciones mediterráneas por las mismas fechas, muchas de ellas envueltas en la difícil Dark Age que siguió al derrumbamiento de la civilización micénica. El hecho es que los asentamientos del Bronce Final tartésico son muy modestos, con casas de cabañas de plantas redondeadas y construidas con materiales ligeros, de modo que desde el punto de vista urbanístico se hace difícil hablar de ciudades. En algunos yacimientos se detecta una incorporación de construcciones de alguna entidad, sobre todo por la existencia de fortificaciones, o alguna otra obra importante de infraestructura urbana, correspondientes al mismo Bronce Final precolonial, o a las etapas en que ya las comunidades tartésicas empezaron a entrar en contacto con los colonos fenicios. Recuérdense los casos de la fortificación de la Mesa de Setefilla, en Lora del Río (Sevilla), que debe adscribirse al Bronce Final (Aubet, Serna, Escacena y Ruiz Delgado, 1983); la de Plaza de Armas de Puente de Tablas, en Jaén (Ruiz Rodríguez, 1987); la de Tejada la Vieja, en Escacena del Campo, Huelva (Blanco y Rothenberg, 1981; Fernández Jurado, 1987); el gran muro de aterrazamiento del Cabezo de San Pedro, de Huelva (Ruiz Mata, Blázquez y Martín de la Cruz, 1981); la fortificación del Bronce Final de la que quedaban restos bajo el gran bastión helenístico de la Puerta de Sevilla, en Carmona (Jiménez, 1989, 167-172); las amplias construcciones empezadas a documentar en Montemolín, en el término de la localidad sevillana de Marchena (Chaves y de la Bandera, 1987); y otros ejemplos.

Sin embargo, si la dimensión monumental o arquitectónica de los establecimientos del Bronce Final tartésico es tan limitada que apenas permite hablar de desarrollo urbanístico, otra cosa es la consideración del nivel urbano, o protourbano, sobre todo desde el punto de vista de la estructura territorial y su organización económica, como se ha dicho. Es desde este punto de 
vista desde el que puede y debe plantearse la relación que puede guardar el Bronce Final tartésico con el orígen del urbanismo hispano.

Además de los niveles de complejidad indicados, una clave importante para determinar si en la organización de este período rigen criterios urbanos radica en comprobar hasta qué punto los establecimientos se ubican en función del comercio intercomunitario, un aspecto que, además, servirá para dilucidar también lo que tenga o no de relación el Bronce Final tartésico con las etapas precedentes.

No hace falta insistir en que un hecho diferenciador principal del fenómeno urbano respecto de estadios anteriores, y definidor de su esencia económica, es la importancia decisiva del comercio interior y exterior. Así se ha puesto de relieve siempre, y se ha subrayado en los estudios modernos sobre la aparición de la vida urbana en las diferentes culturas europeas (por ejemplo, para la Europa central, el libro de Wells, 1988). La atención al cor.ercio será responsable principal de la configuración de la estructura urbana a escala territorial o macroterritorial, en la que tendrán la debida prioridad el estudio y el control de las vías de comunicación, y de la organización de los propios núcleos urbanos, que habrán de disponer de instalaciones adecuadas para el almacenamiento de las mercancías y de lugares para su negociación en espacios amplios de encuentro, llámense ágoras, foros o plazas. Algo se sabe ya, aunque poco, de la organización interna de algunos centros tartésicos, en los que se ha podido excavar en extensión: recuérdese el caso de Tejada la Vieja, que dispuso de almacenes y espacios abiertos al menos en las etapas de maduración de la ciudad, desde fines del siglo VI a.C. (Fernández Jurado, 1987), sin que sea imposible que contara con elementos parecidos en fases más antiguas.

Más factible, e igualmente significativo, resulta analizar las preocupaciones mercantiles a la vista de las pautas de organización territorial. Puede comprobarse que muchos de los centros tartésicos se hallan en lugares que no tienen interés en función de una economía de subsistencia puramente prehistórica. Es más, puede decirse que, bastantes de los principales, ocupan puntos geográficos carentes de recursos inmediatos, en zonas de marismas o costeras de no fácil acomodo, cuya elección sólo se explica por un interés comercial, sea el control de alguna vía importante o una adecuada salida al mar. No es que el interés por las rutas empiece ahora, pero desde ahora es cuestión prioritaria, en función de los imprescindibles contactos a que obliga la economía especializada, el comercio y, en definitiva, la vida urbana. La virtualidad y vigencia de esos criterios explican que la mayoría de estos centros hayan sido desde el Bronce Final puntos de apoyo principales de la estructura urbana del mediodía de nuestra Península, con una generalizada continuidad de ocupación bien comprobada arqueológicamente.

De entre los muchos ejemplos aducibles puede destacarse el de Sevilla, la antigua Hispalis. Es de sobra conocida la incomodidad del lugar, en una mínima elevación sobre el Guadalquivir, que no ha librado a sus habitantes de las inundaciones provocadas por las contínuas crecidas hasta los años presentes, y sólo tras costosísimas obras de ingeniería para reconducir el gigantesco torrente que es, en verdad, el río. Sin embargo, fue una próspera ciudad en la Antigüedad por su verdadero carácter de puerto de mar bastante tierra dentro, en medio de una zona fértil y rica, y abierta a la comunicación con el interior; es la ventaja, destacada elocuentemente por Estrabón 3,2,3, de que hasta ella podían llegar barcos grandes (Abad, 1975). Se conocía que la ciudad tenía orígenes prerromanos (Blanco Freijeiro, 1979), y recientemente se ha comprobado que su fundación es una más de las emprendidas con el Bronce Final tartésico, aunque las dificultades para llegar a niveles profundos han impedido todavía una excavación suficiente como para determinar la entidad del horizonte precolonial (Campos, Vera y Moreno, 1988). 
El asentamiento del Cerro Macareno, en La Rinconada (Sevilla), fue un centro modesto, fundado también en el Bronce Final tartésico hacia el siglo VIII a.C., en un lugar destinado a explotar las ventajas económicas de la vecindad del río Guadalquivir, con condiciones portuarias muy alteradas a fines del milenio que obligaron a abandonar el lugar hacia comienzos del siglo I a.C. En lo excavado se comprueba el fenómeno tantas veces repetido de una fase inicial, de contexto precolonial, constituida por un modesto hábitat de cabañas, seguida de la etapa orientalizante, con casas de planta cuadrangular, mejor construidas, y orientadas con criterios urbanísticos que se mantendrán sin cambios hasta el final de la vida del asentamiento y tras varias superposiciones (Pellicer, Escacena y Bendala, 1983).

Una caso parecido es el del importante yacimiento de la propia Huelva, un centro portuario en medio de la ría, con una especialización como punto de salida al mar de los productos mineros de la sierra, que ha determinado la historia de la ciudad desde su fundación en el Bronce Final hasta nuestros días. San Bartolomé de Almonte representa otro ejemplo similar, y así otros muchos centros principales tartésicos, ubicados en lugares de fácil comunicación con el mar, aunque protegidos de sus embates y aptos para la comunicación interior, para lo que no en vano ocuparon bastantes de los oteros que rodeaban el antiguo Lago Ligustino, desecado en la actual marisma del Guadalquivir. La propia ciudad principal de Tartessos fue erigida en la misma zona, buscando un lugar estratégico a la boca del Guadalquivir, desde donde controlar en las mejores condiciones el flujo económico entre la costa y las ricas tierras del interior accesibles desde el río. No hace falta argumentar ampliamente que esta opción por sitios estratégicos condujo a la ocupación de los citados parajes del bajo Guadalquivir, geológicamente muy inestables, lo que ha dado lugar al complejo problema relativo a la geografía tartésica, tan largamente debatido, y tratado apretadamente por nosotros en un trabajo reciente (Bendala y Corzo, 1991).

El interesante yacimiento del Castillo de Doña Blanca, en el Puerto de Santa María (Ruiz Mata, 1987 a y 1987 b), es un importante centro portuario que mira de cerca a Gadir, y explicable sobre todo en función del control, si se confirma la probable propuesta, del brazo de río que desde este lugar llegaba al Lago Ligustino, cuya existencia resolvería el problema de los dos brazos del río, y la isla en medio de ellos, a los que hacen referencia las fuentes antiguas. Este canal natural proporcionaría una cómoda arteria de navegación que evitaba los peligros de los escollos de la otra desembocadura del Guadalquivir, la actual por Sanlúcar de Barrameda; en el mismo brazo se hallaba un yacimiento tan importante como Mesas de Asta, identificado con Asta Regia, cuya vitalidad se explica también de mejor manera contando con su ubicación sobre el antiguo canal (Chic, 1979; Bendala y Corzo, 1991).

Núcleos tartésicos principales del interior suelen ocupar igualmente enclaves para el control de las rutas por las que discurre el trasiego de las mercancías, principalmente las mineras y metalúrgicas. El ya mencionado centro de Tejada la Vieja es un magnífico ejemplo. Aparte de que sus habitantes aprovecharan las posibilidades mineras de las inmediaciones mismas de la ciudad, muy modestas, su principal papel era controlar un paso natural entre las ricas cuencas mineras del interior de Huelva y las tierras llanas de la costa y el bajo Guadalquivir: es el paso de La Garganta, abierto en la Pata del Caballo, sector onubense de la Sierra Morena. Desde Tejada, la plata y demás productos mineros eran vehiculados hacia los centros y puertos de la costa, ya fueran San Bartolomé o la propia Huelva, ya los situados en torno al Lago Ligustino, que se prolongaba por el actual cauce del Guadalimar hasta bastante cerca de Tejada, si no buscaban directamente el puerto de Gadir (Fernández Jurado, 1987; Ruiz Mata, 1989a). 
También desde el Bronce Final tartésico aparece configurada la importante ruta que se conocerá después como Vía Heraclea o Vía Augustea, vinculada al curso del Tartessos/Betis/Guadalquivir. La jalonan yacimientos principales, como Hispalis (Sevilla), Carmona (últimamente, Pellicer y Amores, 1985), Córdoba (Luzón Nogué y Ruiz Mata, 1973); Epora, en Montoro (Martín de la Cruz, 1987), Cástulo (una síntesis, en: Blázquez y García - Gelabert, 1987) y otros, en los que se documenta, como en los últimos citados, el ejercicio de actividades minerometalúrgicas, que buscan mejor salida alejándose de los núcleos de extracción, por la preferencia de los lugares adecuados para el comercio de sus productos.

En síntesis, sin pretender el análisis de todos los yacimientos -tarea que desbordaría los propósitos del presente trabajo-, parece indudable la creación de una red de centros concebida en función de una estrategia productora y comercial de carácter urbano, que con los demás datos indicados más arriba, documentan la consistencia del nivel urbano o protourbano del Bronce Final tartésico. Quizá en esta vieja raíz de sus ciudades, se cimenta un juicio como el de Estrabón a propósito de los turdetanos, herederos de los tartesios, cuando los ensalza como los más cultos de los iberos, poseedores de leyes y escritos de antigua memoria (Estrabón 3,1,6). Son probables referencias a una antigua politeia que los estudios arqueológicos tienden a confirmar, cuando se comprueba la primacía urbana de Tartessos. Las fuentes literarias, a este propósito, se hacen eco de algunas ciudades tartésicas, de lo que he tratado con alguna extensión en otros lugares (por ejemplo: Bendala, 1986a).

Por otra parte, este es el momento de comentar la cuestión antes planteada sobre cómo se produjo la irrupción de las formas de vida urbanas, o del nivel protourbano que caracteriza al Bronce Final tartésico, cuestión que tiene una faceta principal en la determinación de si ese fenómeno cultural es explicable por evolución de las culturas anteriores o por un impulso externo. La respuesta no es sencilla, como demuestra su discusión científica. En principio, las secuencias estratigráficas no son siempre fáciles de interpretar, como conocen todos los que se hayan ocupado alguna vez de ellas, y a nadie extraña que la interpretación de las estratigrafías obtenidas en El Carambolo, la Colina de los Quemados, la Mesa de Setefilla, Carmona y otros yacimientos expresivos, haya originado ya una densa bibliografía. Es imposible, y casi innecesario, reproducir aquí tan densa discusión, porque, bastante madura ya, los datos tienden a demostrar que existe una franca cesura entre el Bronce Final y las fases anteriores, conforme aumentan aquéllos y pueden ser valorados de mejor manera.

La cesura puede hacerse explícita con la idea de que el poblamiento del Bronce Final se basa en ocupación de lugares nuevos, o de otros con tradición más antigua, pero tras una etapa de hiatus o de atonía en sus manifestaciones arqueológicas. Así lo sostienen estudios recientes sobre el poblamiento de algunas comarcas principales del ámbito tartésico, como los Alcores (Amores, 1982) o sectores de la campiña sevillanos (Ruiz Delgado, 1985). Incluso algunas visiones de conjunto que argumentaron hace poco en favor de la continuidad, y por tanto, de la formación por evolución interna de la primera estructura urbana del Bronce Final tartésico (Escacena, 1983), se han abandonado después por el entendimiento de que la evidencia arqueológica tiende a subrayar los fenómenos de novedad y de ruptura, más que los de continuidad (Belén y Escacena, 1991). Quedan, sin duda, problemas por resolver, como la relación con el horizonte llamado del Bronce Tardío en algunos yacimientos, denominación que puede resultar inadecuada para los de la Andalucía occidental (Martín de la Cruz, 1984-85). No obstante, la novedad del hábitat y del modelo de ocupación territorial que representan es perfectamente explicable en el cuadro de la estrategia urbana acabado de esbozar, en el que se acusa la novedad porque sus 
planteamientos territoriales son inexplicables o imposibles en una economía prehistórica preurbana, e imprescindibles en la urbana.

Remito a la bibliografía citada en el párrafo anterior para un análisis más reposado de la cuestión, o a su consideración por mi parte en otros lugares (Bendala, 1986a y 1986 b), para destacar inmediatamente otro hecho que acompaña al de la ruptura secuencial y del modelo de ocupación territorial, robusteciéndola en sus planteamientos: se trata de la novedad y la carencia de procesos de formación de los elementos más característicos de la cultura material propia del Bronce Final tartésico. Es lo que se deduce del estudio de las cerámicas, principalmente las decoradas con motivos bruńidos y pintados. Plantean no pocos problemas en su valoración, y aunque no falten opiniones que defienden su raigambre local (últimamente: Pellicer, 1987-88 y 1989), parecen más firmes los argumentos genéricamente defendidos sobre la imposibilidad de explicarlas en sus aspectos básicos por un proceso de evolución interna, argumentos que son acompañados habitualmente por la observación de que se muestran desde el principio como productos cerámicos de estilo definido y maduro, sin tanteos previos (Ruiz Mata, 1979 y 198485; Cabrera Bonet, 1981).

También en ésto permanecen bastantes incógnitas por despejar, como la que se plantea ante la convivencia de la radical novedad de las decoraciones pintadas con pervivencias en las formas de tipos anteriores, y otras acerca de una cerámica de rasgos muy definidos y característicos y, por lo demás, de indudable producción local y carente de paralelos exactos en otros lugares. Por otra parte, problemas parecidos a los de las cerámicas pueden ser traídos a colación a propósito de las estelas de guerreros, también un elemento novedoso, con carácter propio, incluible sin duda entre los que otorgan al Bronce Final tartésico su diferenciada e inconfundible personalidad.

Sin embargo, pese a los problemas, haciendo abstracción de lo que queda por resolver, y basándonos en lo que parece bastante probado, puede recapitularse lo dicho y deducir que, en conjunto, el Bronce Final tartésico, tanto por las secuencias estratigráficas y por el modelo de ocupación territorial, como por los elementos que definen su cultura material, se configura como un horizonte nuevo, que irrumpe en el mediodía peninsular con perfiles muy definidos y sin que sea explicable por una evolución interna, por lo que ha de deberse, por tanto, a un impulso externo. En este caso, sin pararse a determinar de dónde procede ese impulso, puede deducirse anticipadamente que si la novedad es aportar una forma de cultura definida en lo esencial por su inspiración urbana, según hemos ido viendo, el impulso ha de proceder de un ambiente también urbano. Y según ello, teniendo en cuenta las fechas y las circunstancias referidas, la procedencia hay que buscarla necesariamente en las culturas urbanas del Mediterráneo oriental. Desde el punto de vista de la dinámica cultural y de las exigencias estructurales, es imposible acudir a zonas no urbanas, como las del Bronce Atlántico, para buscar el orígen de una cultura de base urbana. Puede haber contactos, que los hubo, pero no dependencia como se viene defendiendo en bastantes trabajos recientes, teniendo en cuenta que las culturas centroeuropeas y de la fachada atlántica no alcanzarán niveles urbanos hasta bastante después, en lo que también contarán muy decisivamente las influencias de las civilizaciones mediterráneas (Champion y otros, 1988, 383 y ss.; Peroni, 1989, 462-465).

Recuérdense a este propósito las conclusiones a que han llegado autores como P. Brun, en el estudio de las culturas europeas del mundo céltico. Con principios inspirados también en el historiador F. Braudel, su evolución hacia los sistemas socio-económicos complejos de corte urbano es explicada inmersa en la dinámica de incorporación a las tendencias marcadas por las civiliza- 
ciones mediterráneas, al integrarse el continente en la "économie - monde" promovida y controlada por aquéllas. En esa trayectoria, la incorporación a esa dinámica económica, y a los cambios sociales que ella determina -jerarquización social, aparición de oligarquías y poderes unipersonales, etc.-, se produce escalonadamente en tiempo e intensidad por "círculos": el primero, directamente influido por griegos o etruscos, que incluiría regiones del mediodía francés y de la costa de la Península Ibérica, y otras zonas costeras o inmediatas a ellas; el segundo, que correspondería al conjunto de la Europa céltica continental; y el tercero, el de la Europa atlántica (Brun, $1987,187-197$ y passim).

Volviendo a la cultura que nos ocupa, parece superfluo añadir que la deducción con base estructural de que el impulso urbano no puede proceder sino de las civilizaciones mediterráneas, no colisiona con lo que en general se deduce del estudio arqueológico de las cerámicas o las estelas, en las que tantos elementos reclaman sus vinculaciones con las culturas del Egeo. Es difícil determinar los exactos cauces y los mecanismos por los que llegaron hasta aquí esas influencias o las gentes que las transmitieron, de lo que he tratado en bastantes trabajos, citados más arriba. Pero se va abriendo camino la posibilidad de comprobar la realidad de fenómenos de emigración desde el Mediterráneo oriental hacia Occidente, a partir de la crisis del mundo micénico, siguiendo los «.ninos que los propios micénicos trazaron, y aprovechando, entre otros, los progresos en las técnicas de navegación que harían posible después las colonizaciones históricas (Luzón Nogué y Coín Cuenca, 1986). Quizá las leyendas de los nostoi sean, más que puras leyendas, el recuerdo más o menos novelado de una realidad cultural e histórica, de forma que pueda demostrarse para España un proceso de encuentro y confluencia entre lo que las leyendas sugieren y los datos arqueológicos ponen de relieve, como hace tiempo se viene expresando, ya sin cautelas, en los más modernos estudios de las culturas de la protohistoria italiana (por ejemplo: Colonna, 1974, 282, 295-296; Vattuone, 1987; Bartoloni, 1989, 76 y 82-83; Peroni, 1989, 477).

En cualquier caso, tanto la historia que pudiera hacerse del mismo Bronce Final tartésico, como de las etapas históricas que le sucedieron, puede entenderse en mejores condiciones desde la perspectiva que contempla los acontecimientos como resultado del funcionamiento de una estructura urbana, en contacto con culturas no urbanas -o "bárbaras", siguiendo la expresión clásica aludida al principio- y en proceso de contínuo crecimiento, no sólo como consecuencia de la propia virtualidad interna, sino también de otros impulsos externos, que se incorporan a los que su propio organismo genera.

En principio, una sociedad urbana, o protourbana, implica formas de cohesión social, de relaciones políticas orientadas a sistemas de estado, más o menos evolucionados, que se ponen de manifiesto en la uniformidad y coherencia de los patrones que configuran la cultura material del Bronce Final tartésico, desde la cerámica a las estelas de guerreros. Las excavaciones en marcha permiten, además, observar hechos como la proximidad del tipo de arquitectura defensiva que ofrecen dos yacimientos tan distanciados como Tejada la Vieja, en Huelva, y Plaza de Armas de Puente de Tablas, en Jaén. La práctica identidad del tipo de amurallamiento y los paralelismos en su evolución (desde su orígen en el Bronce Final hasta el añadido de torres cuadrangulares en ambos yacimientos hacia el siglo VI a.C.), apuntan a un fenómeno de gran interés en orden a la mencionada cohesión socio-política del mundo tartésico, que empezamos a detectar ahora y que todavía está por ver en toda su profundidad y complejidad.

Los sistemas de amurallamiento y defensa, y las estelas de guerreros constituyen, además, testimonios materiales de la importancia de una casta de marcado carácter militar en la socie- 
dad tartésica inicial, que demuestran otra vertiente fundamental de la sociedad evolucionada, estatalizada al nivel que fuere: la de un control territorial que había que ejercer para asegurar las materias primas y las actividades económicas dirigidas a su explotación y su comercialización, así como defender el territorio tenido por propio de ataques externos. La vasta distribución geográfica de las estelas de guerreros constituye la mejor demostración de la amplitud de los intereses de los tartesios, en lo que debió contar muy especialmente la atención a las cuencas mineras y, particularmente, la búsqueda del estaño. Ya se ha dicho que es propio de las sociedades urbanas la tendencia expansionista, por una ley multiplicadora de las necesidades de tierra y de materias primas, para asentar los excedentes de población, y para el consumo interno y el mercado exterior.

El desarrollo de la tecnología de las armas, cada vez más accesibles a todos por los crecientes contactos culturales y por el comercio, subrayó el papel de la milicia en las sociedades urbanas, como medio necesario de apoyo a las necesidades de expansión, y de contención de los pueblos vecinos (Champion y otros, 1988, 380-382). La opresión y el afán de control desde las culturas avanzadas, y los propósitos de acercamiento, o de saqueo y de razzia de sus vecinos menos evolucionados, constituyen las dos vertientes del contacto de dos culturas de desarrollo desigual. Es una clásica confrontación entre culturas civilizadas y "bárbaras", que debió experimentarse en la Península desde la configuración del Bronce Final tartésico. Un dato contenido en el viejo periplo de Avieno puede ser un antiguo testimonio escrito de ese fenómeno, cuando refiere (OM 255-259) que los cempsos llegaron a poseer la isla de Cartare, y fueron expulsados de ella después; es un pueblo céltico que llegó, por lo visto, a penetrar hasta la isla comprendida entre los dos brazos del Tartessos/Guadalquivir, donde estaba la capital misma de los tartesios. Tras la expulsión quedaron confinados, seguramente, al otro lado del Guadiana. Hubo de ser más tarde, con la crisis de Tartessos hacia el siglo VI a.C., cuando los celtas debieron de penetrar en territorio tartésico y configurar la región de la Beturia céltica, comprendida en lo esencial entre el Guadiana y el Guadalquivir.

Quizá pueda relacionarse con ese propósito de control territorial y de contención de los pueblos fronterizos, un fenómeno detectado arqueológicamente en los últimos años: antes de la consolidación del Bronce Final tartésico y de su expansión por amplias regiones del mediodía, en el horizonte definido como de Bronce Tardío se detecta una penetración, a veces muy importante, de elementos culturales de orígen meseteño, tipo Cogotas I, que dejan de aparecer precisamente con la maduración de esta primera fase de la civilización tartésica (Molina González, 1978 y 1983; Bendala y Blánquez, 1987; Martín de la Cruz, 1989).

En cuanto a las fricciones por el control territorial con otras culturas urbanas, seguramente las hubo con los fenicios desde que éstos comenzaron su presencia colonial en este extremo del Mediterráneo. Más de una vez se ha sugerido que en el relato transmitido por Posidonio (Estrabón 3,5,5) sobre la fundación de Gadir, se detecta una posible fricción con los tartesios al ser rechazados los fenicios en sus intentos de asentarse hacia Huelva, en las inmediaciones de sus importantes cuencas mineras; si en esta ocasión parece que los tartesios lograron imponer sus criterios, algunas fuentes tardías, como las de Macrobio (Sat. 1,20,12) y Justino $(44,5,1)$, dan cuenta de otros choques en los que fueron los fenicios/cartagineses los que se apuntaron el éxito (Bendala, 1986a, 613-614).

Es un hecho, sin embargo, que la presencia fenicia fue decisiva para la consolidación de la estructura urbana de los tartesios. Habrá que estudiar un aspecto apenas conocido, pero atisbable en algunos ejemplos, consistente en la acomodación por parte de los tartesios de su propia organización 
territorial a las expectativas creadas por la presencia de los fenicios, con el incremento de la fundación de centros destinados a convertirse en puntos de encuentro de ambas sociedades y economías. Quizá Tejada la Vieja, o Hispalis y otros centros se entiendan mejor desde este punto de vista.

En cualquier caso, los colonos semitas fueron, sin duda, el vehículo ideal para el incremento de los beneficios de las oligarquías y su enriquecimiento, bien conocido en la riqueza de sus ajuares funerarios (necrópolis de Huelva, Medellín, Aliseda, etc.). Desde el punto de vista urbanístico, se conoce bien también el paso de los hábitats de cabañas a las estructuras cuadrangulares y a la ordenación y racionalización planimétrica de los poblados y ciudades. Y no debe olvidarse el contacto con los griegos, aunque sean menos aprehensibles sus efectos directos en la sociedad tartésica.

No voy a detenerme, para dar fin a estas páginas, en analizar el desarrollo de la estructura urbana del mediodía a partir de lo que se entiende como crisis del mundo tartésico desde el siglo VI a.C., entre otras cosas porque he tenido ocasión de exponerlo en otros lugares no hace mucho tiempo. Recordaré sólo, resumidamente, cómo la expansión del Bronce Final tartésico hacia la alta Andalucía y el sudeste creó la plataforma que hizo posible el desarrollo de la cultura ibérica clásica, entendible como una prolongación y consolidación de la estructura urbana iniciada desde los focos nucleares tartésicos, con los importantes estímulos que se derivarían de los colonos griegos y púnicos (Abad, 1979; Bendala y Blánquez, 1987).

En la zona nuclear de Tartessos de la baja Andalucía, la crisis de Tartessos abrió un nuevo período de gran complejidad, no bien iluminado todavía por los estudios arqueológicos. Pero todo apunta a sospechar que hubo una pronta recuperación, propiciada sobre todo por una importante penetración cartaginesa, dispuestos los semitas a controlar la creciente estructura urbana del mediodía, animados por ambiciones colonizadoras y de control directo de las tierras y de las fuentes de riqueza minera, que en la etapa arcaica de la colonización fenicia no se quiso o no se pudo emprender. Lo que puede constituir un precedente o un paso previo, se ha documentado ya arqueológicamente, con la presencia de colonias fenicias en el Castillo de Doña Blanca o en Peña Negra, o el fuerte impacto que se percibe en la generalidad de los importantes núcleos del bajo Guadalquivir, con ejemplos tan expresivos como el de Carmona (Bendala, 1987 a).

A la acción cartaginesa debe apuntarse una activa participación en el afianzamiento de la estructura urbana, bien inserta, por lo demás, en una generalizada maduración de la ciudad, desde todos los puntos de vista y en todo el Mediterráneo. La conquista de los Barca cierra este período, con la definición de un episodio fundamental en la historia de la estructura urbana del mediodía al introducir modificaciones inspiradas en criterios helenísticos, con un modelo urbano basado en la gran ciudad -la "megalópolis"-, reflejo de la ambiciosa economía, ya decididamente esclavista, de entonces (Bendala, 1987 a). A la acción púnica, en general, y de los Barca en particular, ha de deberse en buena medida la configuración de un patrón de ciudad relativamente mucho mayor en el sur que en el sudeste y el levante de la Península (Almagro, 1987).

Es, por fin, este estado de cosas, el que hace posible la conquista romana o, más exactamente, la rápida incorporación al Imperio de las regiones del levante y el mediodía peninsulares. La conquista se traduce en la apropiación de una estructura existente, y las dificultades en conquistar el resto de la Península no se deberán a la belicosidad de sus gentes, sino a la carencia de estructura urbana. Roma no podía improvisarla; todo lo más, estimular el proceso de expansión de la estructura urbana de la periferia peninsular hacia el interior, iniciado ya por las culturas de esta zona desde el mismo Bronce Final, y con significativos impulsos de una fuerte penetración 
tierra adentro con los Barca (recuérdense las expediciones de Aníbal). Y acerca de la estructura heredada, es obvio que la única posibilidad era servirse de ella al máximo, incentivando sus propias virtualidades, de modo que es en este plano de continuidad estructural en el que hay que explicar las llamadas "pervivencias" de lo prerromano en lo romano. Completando lo argumentado en otros lugares, concluiré diciendo que no debe abordarse el estudio de la romanización como la creación de una estructura -que es lo que casi siempre se ha hecho, con el arrastre de numerosos malentendidos- sino de cómo incide en la estructura anterior. Será, por otra parte, una incidencia notable, sobre todo cuando acabada la conquista de la Península, su estructura deba acomodarse a la nueva dimensión que supone, no sólo su extensión a toda Hispania, sino su imbricación con el resto del Imperio. Es lo que ocurre en época de Augusto, con quien se puede decir que acaba el proceso de configuración de la estructura urbana básica de Hispania en la Antigüedad (Bendala 1987 b y 1991; Bendala, Fernández Ochoa, Fuentes y Abad, 1987. También, últimamente, el buen estudio de conjunto de Abascal y Espinosa, 1989). Será, además, un punto de partida fundamental para la estructura urbana de España hasta nuestros días. 


\section{BIBLIOGRAFIA}

ABAD CASAL, L. 1975: El Guadalquivir, via fluvial romana, Sevilla.

... 1979: "Consideraciones en torno a Tartessos y el orígen de la cultura ibérica", AEspA 52, 175-193.

ABASCAL, J.M. y EsPinOSA, U. 1989: La ciudad hispano-romana. Privilegio y poder, Logroño.

Almagro Gorbea, M. 1977: El Bronce Final y el periodo orientalizante en Extremadura, BPH XIV, Madrid.

Almagro Gorbea, M. 1987: "El área superficial de las poblaciones ibéricas", Los asentamientos ibéricos ante la romanización, Madrid, 21-34.

Amores Carredano, F. 1982: Carta arqueológica de Los Alcores (Sevilla), Sevilla.

Arteaga Matute, O y Serna, Ma .R. 1974: "Die Ausgrabungen von los Saladares. Prov. Alicante", $M M, 15,108-121$.

... 1975: "Los Saladares, 1971", NAH3, Madrid, 175-193.

Aubet Semmler, Ma ${ }^{\mathrm{a}}$.E. 1987: Tiro y las colonias fenicias de Occidente, Barcelona.

... 1990: "El impacto fenicio en el interior del mediodía peninsular", La cultura tartésica y Extremadura, Cuadernos Emeritenses, 2, Mérida 1990, 29-44.

Aubet Semmler, Mª.E; Serna, Ma ${ }^{a}$.R; Escacena, J.L. y Ruiz Delgado, M.Ma ${ }^{a}$ 1983: La Mesa de Setefilla, Lora del Río (Sevilla). Campaña de 1979, EAE 122, Madrid.

BARTOLONI, G. 1989: La cultura villanoviana. All'inizio della storia etrusca, Roma.

BELEN DeAmos, Ma y EsCaCena CARRASCO, J.L. 1991: "Las comunidades prerromanas de la Baja Andalucía”, Paleoetnologia de la Península Ibérica (Madrid, 1989), Ed. por M. Almagro Gorbea, Madrid, en prensa.

Bendala GaLAN, M. 1977: "Notas sobre las estelas decoradas del Suroeste y los orígenes de Tartessos", Habis 8, 321-330.

... 1979: "Las más antiguas navegaciones griegas a España y el orígen de Tartessos", AEspA 52, 33-38.

... 1981: "La etapa final de la cultura ibero - turdetana y el impacto romanizador", .La baja época de la cultura ibérica, Madrid, 30-48.

... 1986a: "Tartessos", Historia General de España y América, I.1, Madrid, 595-562.

... 1986 b: "La Baja Andalucía durante el Bronce Final", Homenaje a Luis Siret (Cuevas de Almanzora, 1984), Sevilla, 530-536.

... 1987 a: "Los cartagineses en España", Historia General de España y América, I.2, Madrid, 115-170.

... 1987 b:"La cultura en la Hispania romano-republicana. Cuestiones generales", Historia General de España y América, I.2, Madrid, 569-593.

... 1987 c: "Reflexiones sobre los escudos de las estelas tartésicas", Boletín de la Asociación Española de Amigos de la Arqueología 23, 12-17.

... 1990a: "Tartessos hoy a la luz de los datos arqueológicos y literarios", La cultura tartésica y Extremadura, Cuadernos Emeritenses, 2, Mérida, 11-27.

... 1990b: "El plan urbanístico de Augusto en Hispania: precedentes y pautas macroterritoriales", La ciudad romana en Hispania: su monumentalización en época republicana y augustea (DAI, Madrid, 1987), Stadtbild und Ideologie, München, 25-42. 
Bendala Galan, M., Fernandez Ochoa, C., Fuentes Dominguez, A. y Abad Casal, L. 1987: "Aproximación al urbanismo prerromano y a los fenómenos de transición y de potenciación tras la conquista", Los asentamientos ibéricos ante la romanización, Madrid, 121-140.

Bendala Galan, M. y Blanquez Perez, J. 1987: "Los orígenes de la cultura ibérica y un par de notas sobre su arte", Iberos. Actas de las I Jornadas sobre el Mundo Ibérico (Jaén, 1985), Ed. por A. Ruiz y M. Molinos, Jaén, 9-18.

Bendala Galan, M. y Corzo Sanchez, R. 1991: "Paleoetnología de la Andalucía occidental (Etnogeografia)", Paleoetnología de la Península Ibérica (Madrid, 1989), Ed. por M. Almagro Gorbea, en prensa.

Blanco FrejeIro, A. 1979, Historia de Sevilla I(1), La ciudad antigua, Sevilla.

Blanco Frejeiro, A. y Rothenberg, B. 1981: Exploración arqueometalúrgica de Huelva, Barcelona.

Blazquez Martinez, J.Ma. y Garcia GelaberT, M.P. 1987: "El iberismo en la ciudad de Cástulo", Los asentamientos ibéricos ante la romanización, Madrid, 43-54.

BRAUdel, F. 1968: La Historia y las ciencias sociales, Madrid.

BRUN, P. 1987: Princes et princesses de la celtique. Le premier Age du Fer (850-450 av. J.-C.), Paris. CABrera Bonet, P. 1981: "La cerámica pintada de Huelva", Huelva Arqueológica V, 317-335.

Campos Carrasco, J.M., Vera Reina, M. y Moreno Menayo, Ma.T. 1988: Protohistoria de la ciudad de Sevilla. El corte estratigráfico San Isidoro 85-6, Monografías de Arqueología Andaluza/1, Sevilla.

Caro Baroja, J. 1971: "La 'realezày los reyes en la España antigua", Estudios sobre la España antigua, Cuadernos de la Fundación Pastor 17, Madrid, 51-159.

Colonna, G. 1974: "Pre - historia e protostoria di Roma e del Lazio", Popoli e civiltà dell'Italia antica, Roma, 273-317.

Champion, T., Gamble, C., Shenan, S. y Whittle, A. 1988: Prehistoria de Europa, Barcelona.

Chaves Tristan, Fa. y De La BANDera Romero, Ma.L. 1987: "Excavación en el yacimiento arqueológico de Montemolín (Marchena, Sevilla)", Anuario Arqueológico de Andalucía I 1985, Sevilla, 1987, 369-375.

CHIC, G. 1979: "Gades y la desembocadura del Guadalquivir", Gades 3, 7-23.

ESCACENA CARRASCO, J.L. 1983: "Problemas en torno a los orígenes del urbanismo a orillas del Guadalquivir", Gades 3, 39-83.

FernandeZ Jurado, J. 1987: Tejada la Vieja: una ciudad protohistórica, Huelva Arqueológica IX.

Fustel De Coulanges, N.D. 1983: La ciudad antigua, Madrid (De las muchas ediciones de esta obra clásica, publicada en 1864 , me he servido de esta versión, editada por Iberia y traducida por C.A. Martín).

Galvan, V. 1986: "Análisis de pastas cerámicas", en Ruiz Mata y Fernández Jurado, 1986, 275-331.

GonZalez Prats, A. 1983: Estudio arqueológico del poblamiento antiguo de la Sierra de Crevillente, Anejo I de la Revista Lucentum, Alicante.

Gonzalez Prats, A. 1990: Nueva luz sobre la Protohistoria del Sudeste, Alicante.

Jimenez Martin, A. 1989: La Puerta de Sevilla en Carmona, Sevilla.

Luzon Nogue, J.Ma y RuIz MATA. 1973: Las raíces de Córdoba. Estratigrafia de la Colina de los Quemados, Córdoba.

LuZON Nogue, J.Ma y CoIN CuenCA, L.M. 1986: "La navegación preastronómica en la Antigüedad: orientación de pájaros en la orientación náutica”, Lucentum 5, 65-85. 
Martin de la CruZ, J.C., 1987: El LLanete de los Moros (Montoro, Córdoba), EAE 151, Madrid.

Martin de la Cruz, J.C. 1984-85: "Problemas en torno a la definición del Bronce Tardío en la baja Andalucía”, Cuadernos de Prehistoria y Arqueología de la Universidad Autónoma de Madrid (CuPAUAM), 11-12, 205-215.

MARTIN DE LA CRUZ, J.C., 1988: "Mykenische Keramik aus bronzezeitlichen Siedlungschichten vom Montoro am Guadalquivir”, $M M 29,77-92$.

Martin DE LA CRUZ, J.C. 1989: "El Bronce en el valle medio del Guadalquivir", Tartessos. Arqueologia protohistórica del bajo Guadalquivir, Barcelona, 121-143.

MARTIN DE LA CRUZ, J.C. 1990: "Die erste mykenische Keramik von der Iberischen Halbinsel”, Praehistorische Zeitschrift 65, 49-52. Y trabajos analíticos del mismo número, por Ch. Podzuweit y $\mathrm{H}$. Mommsen y otros, 53-61.

Molina Gonzalez, F. 1987: "Definición y sistematización del Bronce Tardío y Final en el Sudeste de la Península Ibérica”, Cuadernos de Prehistoria de la Universidad de Granada, 3, 159-232.

Molina Gonzalez, F. 1983: "Prehistoria de Granada”, en Historia de Granada I, Granada, 3-141.

Pellicer CATAlan, M. 1987-88: "Las cerámicas a mano del Bronce Reciente y del orientalizante en Andalucía occidental”, Habis 18-19, 461-483.

Pellicer Catalan, M. 1989: "El Bronce Reciente y los inicios del Hierro en Andalucía occidental”, Tartessos. Arqueología protohistórica del bajo Guadalquivir, Barcelona, 147-187.

Pellicer Catalan, M. y Hurtado Rodriguez, V. 1980: El poblado metalúrgico de Chinflón (Zalamea la Real, Huelva), Universidad de Sevilla.

Pellicer Catalan, M., Escacena Carrasco, J.L. y Bendala Galan, M. 1983: El Cerro Macareno, EAE 124, Madrid.

Pellicer Catalan, M. y Amores Carredano, F. 1985: "Protohistoria de Carmona. Los cortes estratigráficos CA-80/A y CA-80/B”, Noticiario Arqueológico Hispánico 22, Madrid, 55-189.

Rovira LLORENS, S. 1987: "Algunos aspectos de la tecnología metalúrgica en el Bronce Final y la Edad del Hierro", Boletín de la Asociación Española de Amigos de la Arqueologia, 23, 53-57.

Ruiz Delgado, M.Ma. 1985: Carta arqueológica de la campiña sevillana. Zona sureste I, Sevilla.

Ruiz MatA, D. 1979: "El Bronce Final -fase inicial- en Andalucía occidental. Ensayo de definición de sus cerámicas", $A E s p A$ 52, 3-19.

Ruiz Mata, D. 1981: "El poblado metalúrgico de época tartésica de San Bartolomé (Almonte, Huelva)", $M M 22,150-170$.

Ruiz MATA, D. 1987a: "La formación de la cultura turdetana en la Bahía de Cádiz a través del Castillo de Doña Blanca”, Iberos. Actas de las I Jornadas sobre Mundo Ibérico (Jaén, 1985), Jaén, 299-314.

RUIZ MaTA, D. 1987 b: "Informe sobre las excavaciones sistemáticas realizadas en el yacimiento del Castillo de Doña Blanca (Puerto de Santa María, Cádiz)”, Anuario Arqueológico de Andalucial1986, II, Sevilla, 360-365.

Ruiz MATA, D. 1989a: "Huelva: un foco temprano de actividad metalúrgica durante el Bronce Final”, en Tartessos. Arqueología protohistórica del bajo Guadalquivir (MaE.Aubet coord.), Barcelona, 209-243.

Ruiz Mata, D. 1989 b: "El túmulo 1 de la necrópolis de 'Las Cumbres'(Puerto de Santa María, Cádiz)", en Tartessos. Arqueología protohistórica del bajo Guadalquivir, Barcelona, 287-296.

Ruiz Mata, D., Blazquez Martinez, J.Ma. y Martin De La CruZ, J.C. 1981: "Excavaciones en el Cabezo de San Pedro (Huelva). Campaña de 1978”, Huelva Arqueológica V, 149-316. 
Ruiz-Galvez Priego, M. 1990: "La metalurgia de Peńa Negra I", en González Prats, 1990, 317-357.

RuIz Rodriguez, A. 1986: "Ciudad y territorio en el poblamiento ibérico del Alto Guadalquivir", Los asentamientos ibéricos ante la romanización, Madrid, 9-19.

RYKWERT, J. 1985: La idea de ciudad. Antropologia de la forma urbana en el Mundo Antiguo, Madrid.

SPENGLER, O. 1966: La decadencia de Occidente, Madrid.

VATTUONE, R. 1987: "L'immagine della città. Aspetti e problemi di storiografia antica", La formazione della città in Emilia romana, Bolonia, 1987, 115-130.

WELLS, P.S. 1988: Granjas, aldeas y ciudades. Comercio y origenes del urbanismo en la protohistoria europea, Barcelona. 